\title{
Forms of Becoming: The Evolutionary Biology of Development
}

\author{
Alessandro Minelli. 2009. Princeton University Press, Princeton and London. Pp. 242, 17 line drawings. US\$29.95 \\ (cloth). ISBN 9780691135687.
}

Reviewed by Raymond Pierotti

Reviewer Address: Department of Ecology and Evolutionary Biology, University of Kansas, Lawrence, KS 66045

Received: February 20, 2012

Volume 3:35-38

Published: June 26, 2012

(C) 2012 Society of Ethnobiology

The embryo is key to the adult. This idea has been at times, and probably always should have been, a basic principle of biological thinking. Darwin considered development to be crucial to understanding evolution, however, Darwinian thinking did not include a useful concept of heredity, therefore the discovery of genes and the growing influence of genetics in biology during the early part of the 20th century, caused both the Darwinian concept of natural selection and the potential importance of developmental biology to fall into eclipse. The study of development became descriptive and generalized, which meant it was not used as a means to understand the generation of individual variation. Finally in the 1980s, the discovery of Hox genes provided a mechanism that directly linked DNA with development, thus providing the stimulus for a "new" discipline, referred to as Evolutionary Developmental Biology, or Evo/Devo for short.

The most important aspect of Evo/Devo is that it provides new insight into how variation in morphometric traits is generated among individuals within a species and provides a mechanistic explanation for phenotypic plasticity, the means by which a single genotype can produce more than one phenotype, depending upon environmental conditions. An interesting aspect of Minelli's Forms of Becoming is that, rather than focusing on the production of variable phenotypes and the role of genes in development, Minelli frames the debate in terms of an earlier argument between Cuvier and St. Hillaire in France in the years from the French Revolution to the publication of Darwin's Origin of Species in 1859. For those of you who have remained largely ignorant of the internal politics of the Musee d'Histoire Naturelle during the early 19th century this debate was of interest because it remains with us, only today it is disguised as Creation "Science" vs. Evolution as a Process. The basic story is that Etienne Geoffrey St. Hillaire was appointed Musee Chair in Vertebrate Zoology in 1793. St. Hillaire recommended his senior colleague Georges Cuvier for appointment to the Professorship of Comparative Anatomy. Ironically, the position of Professor of Invertebrate Zoology was given to the plant expert Jean-Baptiste Monet de Lamarck, who probably should be recognized as the originator of the concept of phenotypic plasticity. Lamarck's advocacy of the role of phenotypic plasticity in evolution makes more sense if we consider that he was at heart a botanist. This knowledge places his otherwise naïvesounding arguments about neck length in giraffes in a better context, if we realize that what he really had in mind was floral forms and leaf shapes, which are quite variable, and in some cases new variants can be passed across generations. Plants do not initiate a separate germ line early in their development the way animals do. Thus, somatic mutations in plants can be incorporated into future germ lines and acquired traits can readily be inherited across generations.

Problems arose because Cuvier identified four basic groups of animals: vertebrates, articulates (arthropods and worms), molluscs, and radiates (Echinoderms and Cnidarians), and contended that these four groups were distinct and could not be usefully compared to one another in terms of anatomical features, thus negating the use of homology and removing a major source of evidence for evolutionary change. In essence, Cuvier felt that once an organism, or form, existed, it could not change. In contrast St. Hillaire argued that nature was far more mutable and that all of these different forms were in fact, animals, and hence shared a history. St. Hillaire believed in a common descent as shown through structural design, and that even major differences between organisms might be revealed to show common ancestry, which was as radical a concept in 
Napoleon's France as it later proved to be in Victorian England. Minelli points out that this debate was settled in Cuvier's favor; more important to us today, the debate was reopened during the last years of the twentieth century, when the discovery of Hox genes revealed that all living creatures, and certainly animals, did in fact share a master plan.

In contemporary biology, Evo/Devo has become linked to the origins of phenotypic plasticity and is thus recognized as a major factor in generating the variation among individuals upon which natural selection can act. The most exciting thing is that we now have the beginnings of a theory that can explain differences in life history and behavior, which have always been the aspects of a phenotype with the lowest heritability, and hence are the features most heavily influenced by the environment.

This last point should be of special interest to ethnobiologists because Indigenous peoples have long recognized that the environment influences the appearance and behavior of local plants and animals. The Teton Lakota Okute stated that, "All birds, even those of the same species, are not alike, and it is the same with animals, and with human beings. The reason Wakan Tanka does not make two birds, or animals, or human beings exactly alike is because each is placed here to be an independent individual and to rely upon itself... From my boyhood I have observed leaves, trees, and grass, and I have never found two alike. They may have a general likeness, but on examination I have found that they differ slightly. It is the same with animals" (McLuhan 1971, cited in Pierotti 2011). In this statement, Wakan Tanka should probably be read as Nature, rather than as "god", the way many anthropologists and Christianized Lakota people may interpret this term today.

In Forms of Becoming, Minelli advances a related argument: "Evolutionary history does not follow a plan, but lays out a pattern whose logic can only be interpreted after the fact" (p. 78), which basically states his premise that the basis of individuality lies in the developmental process, and that development is to the individual as phylogeny is to a species. Following this theme, Minelli honors Haeckel's once discredited idea that "ontogeny recapitulates phylogeny," which Minelli likens to a soap opera, in which the beginning of the 2nd episode briefly summarizes the first and so on, such that the nth episode provides a summary of all previous episodes, spending slightly more air time on the $\mathrm{n}$-1 th episode.
Stephen Jay Gould resurrected Haeckel's principle in his Ontogeny and Phylogeny (1977) by raising the question of how timing of developmental effects was important in macroevolution. Where I find Haeckel's principle most useful is in pointing out that mammalian embryos do not undergo a stage showing features of birds or even those of modern reptiles, because mammals (and their ancestors) evolved well before birds and that contemporary reptiles (except turtles) come from a separate lineage, the diapsids, so that neither of these groups is ancestral to mammals in any way, thus their embryonic stages are not a part of mammalian phylogeny.

Ontogeny was largely ignored by evolutionary biologists during all but the last decade of the $20^{\text {th }}$ century because of the preeminence of genetics and "gene-based" thinking in evolutionary thought. This approach once seemed productive, but recent discoveries have revealed weaknesses, and as Minelli points out, we have passed from the Mendelian gene, which was sort of a black box, to "The Central Dogma" of DNA, mRNA, and transcription and translation resulting in enzymes and structural proteins, and now to Evo/Devo in which genes are considered to be flexible in function and may not always generate the same product if they act in different environments. Given these differences Minelli asks, "to what extent biologists educated in different research traditions such as population genetics, molecular genetics, and developmental biology are aware...that they are really talking entities that differ markedly... of concepts...that are part of research paradigms without much in common" (p. 97). Minelli argues that this contemporary redefinition of gene action reveals "why (Evo/Devo) can become a terrain of rigorous critical revision... as regards the topic of the gene" (p. 97).

Minelli is a scholar of the evolution of animal form at the University of Padua (this book was originally published in Italian as Forme de Devinere), therefore, his knowledge of development is solidly grounded. His specialization seems to be on modularity and body form in segmented invertebrates, and many of his examples are drawn from centipedes and leeches, organisms that basically repeat the same bodily unit a number of times. As such, these organisms are ideal for examining the functioning of homeobox (HOX) genes, which regulate the production of specific organs and are found in all bilateral animals, including echinoderm larvae. The only difficulty, however, is 
that for Ethnobiologists the extensive discussions of invertebrate body types will seem a bit arcane.

Another, more serious, issue is that this book lacks a bibliography, and only contains a short set of recommended readings for each chapter, so the interested reader will find it very difficult to seek out the sources of some of the interesting examples or points of theory.

If Forms of Becoming does not provide nonspecialists with user-friendly access to the science of Evo/Devo, what are the alternatives? Ironically, one factor that stimulated evolutionary biologists to carefully explore the issue of Evo/Devo was the sequencing of complete genomes, including the human genome. Since the 1970s molecular biology has been very productive and always seemed to promise great insights into the process of evolution. This promise was based upon the notion that complex organisms could be best understood by examining their constituent parts, and DNA sequencing promised to reduce life to its simplest components and allow us to understand the true nature of living organisms. As soon as sequencing became well established, it was obvious that genomes (and living creatures) were much more complicated than had been promised. Many molecular biologists became frustrated and confused at how unintuitive, complex, and apparently inefficient genomes really seem to be, and that sheer masses of information will not resolve central questions in biology.

One voice that had predicted this state of affairs and recognized the importance of Evo/Devo was the superb but controversial Evolutionary Geneticist, Richard Lewontin. In his book The Triple Helix (2000), Lewontin laid out the basis of Evo/Devo and established that the only way to understand living systems was to recognize that they arise at the intersection of multiple weak forces. It is important to emphasize that "weak" is not used in the sense of unimportant, but in the sense that they are not strongly deterministic and do not necessarily always produce the same outcome.

Perhaps the most innovative argument of Lewontin's is that we should change our conception of an environment that creates conditions to which an organism must respond, and recognize that organisms shape and change their environments as well as the other way around. It is this interaction between "genes" and their local environment (including local environments experienced within the body by individual cells and tissue types) that produces the variable phenotypes we observe, and also reveals that genes are the least variable aspect of the triad of gene, organism and environment that provides the metaphor that underlies his title.

Minelli presents an analogous argument that is not as clearly laid out as Lewontin's in his discussion of pleiotropy, in which many characteristics are affected by the actions of the same gene really depends on our definitions of both "characteristic" and "gene" (p. 121). Minelli explains pleiotropy using an analogy of how an electrician has multiple effects on the construction of a house that may have made more sense in the original Italian. Minelli is correct in pointing out that "genes" are more complex entities than we realize, but his explanations are nowhere near as elegant as those found in The Plausibility of Life: Resolving Darwin's Dilemma, published in 2005 by Marc Kirschner and John Gerhart, Systems Biologists from Harvard and UC Berkeley, respectively.

The Plausibility of Life provides the best explanations I have read of how molecular and cellular processes interact to produce variable phenotypes at each level from physiological to morphological to behavioral. For anyone who feels intimidated by detailed discussions of molecular genetics, this text provides a user-friendly approach to discussion of the genetics of development and how they produce variable individuals by using the same basic plan and show how variations that occur during the developmental process are probably much more important than genetic mutations in producing variants upon which selection can act. This idea is very important in that it is now possible to connect phenotypic variation and plasticity with genetic processes to produce adaptive traits without having to rely on fortuitous mutations.

For Ethnobiologists, The Plausibility of Life will provide useful insights at the cellular or molecular level in understanding phenotypic variation, but most ethnobiological work involves phenomena at higher levels of organization such as ecology and behavior. Fortunately in 2011 another new text, The Flexible Phenotype by the Dutch Physiological Ecologists Theunis Piersma and Jan van Gils, became available. This book expands upon Lewontin's idea of the interaction between the organisms and its environment from the perspective of ecology. Piersma and van Gils also provide an evaluation (Table 6) of most of the texts available that discuss the evolution of phenotypic plasticity (interestingly they do not include Minelli's Forms of Becoming). 
I suspect that this last omission is because Minelli's work is too esoteric and specialized to provide insights to students of ecology and behavior. Accordingly I would advise most readers of this review to look at Kirschner and Gerhart (2005) and Piersma and van Gils (2011) if they want to learn why Evo/Devo and phenotypic plasticity are of relevance to both evolutionary biology and to their own studies.

\section{References Cited}

Gould, S. J. 1977. Ontogeny and Phylogeny. Belknap Press of Harvard University Press, Cambridge, MA.

Kirschner, M.W. and J. C. Gerhart. 2005. The Plausibility of Life: Resolving Darwin's Dilemma. Yale University Press, New Haven, CT.

Lewontin, R. 2001. The Triple Helix: Gene, Organism, and Environment. Harvard University Press, Cambridge, MA.

Piersma, T. and J.A. Van Gils. 2011. The Flexible

Phenotype: A Body-Centered Integration of Ecology, Physiology, and Behaviour. Oxford University Press, New York, NY. 